\title{
Comparative Antiradical Activity and Molecular Docking Study of Bergaptol and Xanthotoxol
}

\author{
$\check{Z ̌ i k o ~ M i l a n o v i c ́ ~}^{1 *}$, Marko Antonijević ${ }^{2}$ Jelena Đorović², Dejan Milenković \\ ${ }^{1}$ University of Kragujevac, Faculty of Science, Department of Chemistry, 12 Radoja \\ Domanovića Street, 34000 Kragujevac, Serbia \\ e-mail: ziko.milanovic@pmf.kg.ac.rs \\ ${ }^{2}$ University of Kragujevac, Institute of Information Technologies, Department of Science, \\ Jovana Cvijića bb, 34000 Kragujevac, Serbia \\ e-mail: mantonijevic@uni.kg.ac.rs, jelena.djorovic@uni.kg.ac.rs,dejanm@uni.kg.ac.rs \\ *corresponding author
}

\begin{abstract}
The antioxidant activity of bergaptol (4-hydroxyfuro[3,2-g]chromen-7-one, BER) and xanthotoxol (9-hydroxyfuro[3,2-g]chromen-7-one, XAN) was investigated in water and benzene, as solvents. For this purpose, the density functional theory (DFT) was used. The free radical scavenging potency of investigated compounds towards different reactive oxygen species (ROS) was performed. Antioxidative mechanism of investigated compounds hydrogen atom transfer (HAT), single-electron transfer-proton transfer (SET-PT) and sequential proton loss electron transfer (SPLET) were examined using M06-2X/6-311++G(d,p) theoretical model. The important thermodynamic parameters (BDE, IP, PDE, PA, ETE) and Gibbs free energies of reactions, were used to determine the most probable antioxidant mechanism of action. The obtained thermodynamic parameters suggested that Hydrogen Atom Transfer (HAT) is the most probable reaction pathway in benzene, while Sequential Proton Loss Electron Transfer (SPLET) was favorized in water. The obtained results indicate that the favorable mechanism of antiradical activity depends on the polarity of medium and the nature of free radical species. By comparing the antioxidant activity of investigated compounds, it can be concluded that bergaptol exhibits better antioxidant properties. Molecular docking study of neutral and anionic species of investigated compounds was performed according to Estrogen receptor alpha $(E R \alpha)$. In both cases, bergaptol showed better inhibitory potency. All the anionic species showed a higher inhibition constant, indicating lower inhibition potency than corresponding parent molecules.
\end{abstract}

Keywords: bergaptol, xanthotoxol, DFT, antioxidant, estrogen receptor alpha

\section{Introduction}

Reactive oxygen species (ROS) are generated in cells metabolism of aerobic organisms. At physiological concentrations, they have an important role in normal cell function as mediators of intracellular signaling cascades (Turrens, 2003). Excessive production and accumulation of 
ROS may lead to oxidative stress which causes loss of normal cell function. Consequently, oxidative damage of cells significantly contributes to multiple pathologies such as inflammatory disease, cardiovascular disease, cancer, diabetes, Alzheimer's disease, cataracts, autism, and aging (Liou et al., 2010, Apel et al., 2004). To prevent or reduce the ROS induced oxidative damage, the aerobic organisms have developed an antioxidant defense system that includes specific intracellular enzymes. On the other hand, specific molecules-antioxidants can neutralize free radicals via different mechanisms of antioxidant activity (Bian et al., 2009).

Coumarins (known as 1,2-benzopyrones), consisting of fused pyrone and benzene rings, are an important group of low-molecular weight compounds and have been widely used for the prevention and treatment of many diseases (Kostova et al., 2011). The specific class of these compounds is furanocoumarins who are consist of a furan ring fused with a coumarin base. A handful of plant families such as Apiaceae and Rutaceae contein the largest numbers of different furanocoumarins. Several reviews summarize advances in the application of coumarins, especially concerning their antioxidant properties (Pathak et al., 1962).

Several recently published review articles show advances in the application of coumarins, especially concerning their antiradical properties (Pathak et al., 1962). The different bioactive compounds isolated from grapefruit juice and grapefruit peel oil have shown significant antioxidant capacity. One of the structures was elucidated and identified as bergaptol (4hydroxyfuro[3,2-g]chromen-7-one, BER). The isolated compound was tested for their radical scavenging activity using 2,2-azobis (3-ethylbenz-thiazoline-6-sulfonic acid) (ABTS) and 2,2diphenyl-1-picrylhydrazil (DPPH) methods at different concentrations. Bergaptol showed very good radical scavenging activity at all the tested concentrations (Girennavar et al., 2007).

A variety of furanocoumarin isolated from the Chinese herbs were tested for antiradical activity and the ability to inhibit lipid peroxidation in rat brain and kidney homogenates as well as rat erythrocyte hemolysis. One of the isolated compounds xanthotoxol (9-hydroxyfuro[3,2g]chromen-7-one, XAN) was exhibited potent antioxidative activity in both, lipid peroxidation and hemolysis assays (Devienne et al.,2007).



BER<smiles>O=c1ccc2cc3ccoc3c(O)c2o1</smiles>

XAN

Fig. 1.Structures of bergaptol (BER) and xanthotoxol (XAN) with atomic numbering

This study aims to examine the antioxidant properties of bergaptol and xanthotoxol in benzene and water and to determine how the $\mathrm{OH}$ group in a different position contributes to antioxidant capacity. The reaction of $\mathrm{H}$ atom transfer from $\mathrm{A}-\mathrm{OH}$ can obey at least three different mechanisms: hydrogen atom transfer (HAT(1)), single-electron transfer followed by proton transfer $($ SET-PT $(\mathbf{2}, \mathbf{3})$ ), and sequential proton loss electron transfer (SPLET $(\mathbf{4}, \mathbf{5})$ ).

$$
\begin{gathered}
A-\mathrm{OH} \rightarrow A-\mathrm{O}^{+}+{ }^{+} \\
A-\mathrm{OH} \rightarrow \mathrm{A}-\mathrm{OH}^{+}+e^{-}
\end{gathered}
$$




$$
\begin{gathered}
A-O H^{+} \rightarrow A-O+H^{+} \\
A-O H \rightarrow A-O^{-}+H^{+} \\
A-O^{-} \rightarrow A-O+e^{-}
\end{gathered}
$$

All present mechanisms are competitive and depend on the reaction conditions, as well as on the properties of solvents and free radicals (Klein et al., 2007). In addition, antioxidant properties were investigated in reaction with various reactive oxygen species such as hydroxyl $(\mathbf{O H})$, hydroperoxy $(\mathbf{O O H})$, methoxy $\left(\mathrm{OCH}_{3}\right)$, methyl peroxy $\left(\mathrm{OOCH}_{3}\right)$, vinil peroxy $(\cdot \mathrm{OOCHCH})$, iso-propoxy $\left(\mathrm{OCH}\left(\mathrm{CH}_{3}\right)_{2}\right)$ following equation:

$$
\begin{gathered}
A-\mathrm{OH}+\mathrm{OR} \rightarrow A-\mathrm{O}^{+} \mathrm{ROH} \\
A-\mathrm{OH}+\mathrm{OR} \rightarrow A-\mathrm{OH}^{+}+\mathrm{OR} \\
A-\mathrm{OH}^{+}+\mathrm{OR} \rightarrow A-\mathrm{O}^{-} \mathrm{ROH} \\
A-\mathrm{OH}+\mathrm{OR} \rightarrow A-O^{-}+\mathrm{ROH} \\
A-O^{-}+\mathrm{OR} \rightarrow A-\mathrm{O}^{-} \mathrm{OR}
\end{gathered}
$$

In Eqs (1) - (10) $\mathbf{A}-\mathbf{O}, \mathbf{A}-\mathbf{O}^{-}$, and $\mathbf{A}^{-\mathbf{O}^{+\cdot}}$ represent the free radicals, anions, and radical cations issued from the corresponding phenolic $(\mathrm{A}-\mathrm{OH})$ compounds. In addition, a molecular docking study was used to investigate the ability and binding mode of investigated compounds to biological important estrogen receptor alpha (ER $\boldsymbol{\alpha})$. A detailed description of the interactions between investigated compounds and protein can help in a better understanding of the biological effects of these components. Special attention is paid to the effect of a hydroxyl group in different positions attached to an aromatic ring of furanocoumarin bases on the stability of the protein-ligand complex.

\section{Methodology}

\subsection{Thermodynamic parameters of antiradical activity}

All quantum chemical calculations were performed using the Gaussian 09 software package (Frisch et al., 2010). The hybrid meta M06-2X functional was used for geometry optimization and computation of harmonic vibrational frequencies using the $6-311++G(d, p)$ basis set (unrestricted M06-2X) for the resulting radicals. The applied level of theory was used for the optimization of each neutral molecule and the related radicals, radical cations, and anions. Previous studies have shown that the M06-2X method is suitable for thermochemical and kinetic research (Zhao et al., 2008). To determine stationary points on the potential energy surface for all optimized structures the harmonic vibrational frequencies were calculated. All structures were optimized in two different solvents: benzene $(\varepsilon=2.2706)$, water $(\varepsilon=78.3553)$, without any geometrical constraints using the CPCM solvation model (Takano et al., 2005). These solvents were selected to mimic the polar and nonpolar surroundings as well as conditions of experimental measurements. It is well established that the antioxidant activity of a compound rather depends on a microenvironment of the reaction medium, and not just of its structure and nature of the involved ROS.

The thermodynamical parameters relevant for the investigated antioxidative mechanisms (BDE, IP, PDE, PA, and ETE) were calculated from total enthalpies of the optimized species using the following equations: 


$$
\begin{gathered}
B D E=H(A-O)+H(H)-H(A-O H) \\
I P=H\left(A-O H^{+}\right)+H\left(e^{-}\right)-H(A-O H) \\
P D E=H(A-O)+H\left(H^{+}\right)-H\left(A-O H^{+}\right) \\
P A=H\left(A-O^{-}\right)+H\left(H^{+}\right)-H(A-O H) \\
E T E=H(A-O)+H\left(e^{-}\right)-H\left(A-O^{-}\right)
\end{gathered}
$$

On the other hand, the thermodynamical parameters relevant to the investigated antioxidative mechanisms with different radical species were calculated from the difference between free energies of the optimized products and reactants using the following equations:

$$
\begin{gathered}
\Delta_{r} G_{B D E}=G(A-O)+G(R O H)-G(A-O H)-G(\text { OR }) \\
\Delta_{r} G_{I P}=G\left(A-O H^{+}\right)+G(O R)-G(A-O H)-G(\text { OR }) \\
\Delta_{r} G_{P D E}=G\left(A-O^{-}\right)+G(R O H)-G\left(A-O H^{+}\right)-G(\text { OR }) \\
\Delta_{r} G_{P A}=G\left(A-O^{-}\right)+G(R O H)-G(A-O H)-G(\text { OR }) \\
\Delta_{r} G_{E T E}=G(A-O)+G(O R)-G\left(A-O^{-}\right)-G(O R)
\end{gathered}
$$

where RO• denotes the reactive oxygen species (Đorović et al, 2014). The Gibss free energies of the examined reactions were determined at standard conditions ( $T=298.15 \mathrm{~K}$ and $p=101325$ $\mathrm{Pa})$ as the difference between the sum of the Gibss energy of products and the reactants. If the reaction of the exergonic, $\Delta_{\mathrm{r}} G<0$, or isoergonic, $\Delta_{\mathrm{r}} G \leq 0$, this means that the newly formed radical is more stable than the initial, indicating that the reactive path is favored (Tošović et al.,2018)

\subsection{Molecular docking}

AutoDock 4.2. program package was utilizing for molecular docking simulations (Morris et al., 2009). The search for possible target proteins was performed using online server SwissTargetPrediction. This strategy is based on accurately identify and quantify the similarity between the investigated molecule and the known ligands (Gfeller et al.,2014). The crystal structure of Estrogen receptor alpha (ERo) was taken from RCSB Protein Data Bank with PDB code 3ERT (Shiau et al.,1998). To prepare the receptor file (to select the needed chains, delete multiple ligands and non-protein parts) the Discovery Studio 4.0 (BIOVIA Discovery Studio 2016) was used. For simulations, the optimized structures of investigated compounds (Fig.2) were taken. Before the docking simulations, Autodock tools (ADT) was used to add Kollman united atom charges and polar hydrogen atoms to the prepared selected receptor. The grid box of dimensions $60 \times 60 \times 60 \AA$ along the XYZ directions with a grid spacing of $0.375 \AA$ was created using the AutoGrid module. For the search, the conformers with the lowest energy Lamarckian Genetic Algorithm (LGA) was selected. 


\section{Results and discussion}

\subsection{Frontier molecular orbitals and global reactive parameters}

The optimized structures of the investigated compounds are presented in Fig.2. Both structures have planar psoralen bases with a free $\mathrm{OH}$ group attached to the aromatic ring. The structure of xanthotoxol is stabilized with very weak intramolecular hydrogen bond between $\mathrm{OH}$ group and the oxygen atom of pyrone ring $(2.23 \AA)$.



BER

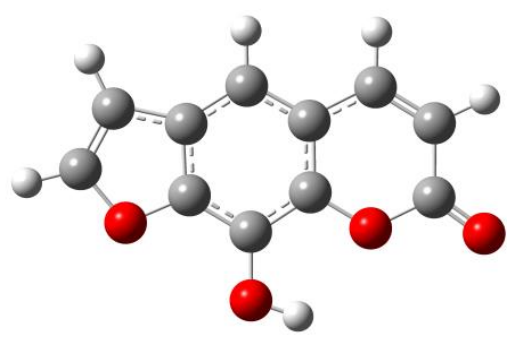

XAN

Fig. 2. The optimized structure of bergaptol (left) and xanthotoxol (right) in water obtained at the M06-2X/6-311++G(d,p) level of theory

The HOMO and LUMO orbitals and their difference in energy, are important parameters for the prediction of the general reactivity of molecules (Dimić et al., 2017; Wang, et al.,2019). The higher energy of HOMO orbital implies that the molecule is a better electron donor. The lowest difference in energy or HOMO-LUMO gap signifies the most reactive molecules, while the large energy gap value implies high stability (Karelson, et al., 1996). If we compare the results presented in Table 1, it can be concluded that the bergaptol molecule is more reactive than xanthotoxol with an energy gap of $6.26 \mathrm{eV}$.



BER-HOMO (-7.53)

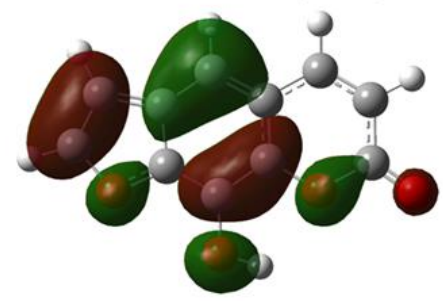

XAN-HOMO (-7.59)

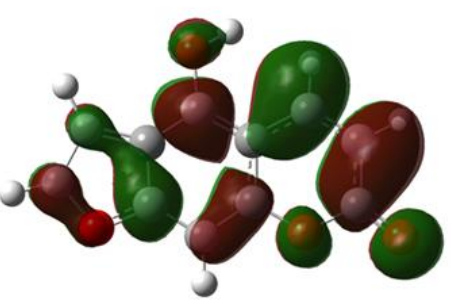

BER-LUMO (-1.27)

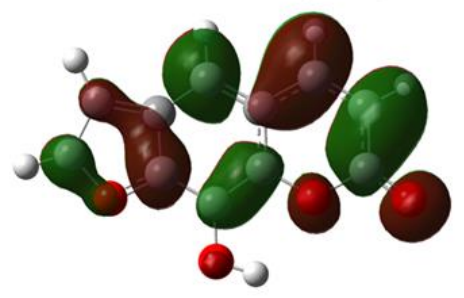

XAN-LUMO (-1.27)

Fig.3. The HOMO and LUMO orbitals of bergaptol (BER) and xanthotoxol (XAN) with orbital energies in $\mathrm{eV}$ 
On the other hand, general reactivity parameters can be a useful tool for the theoretical comparison of a group of molecules. Ionization potential (I), vertical electron affinity (A), chemical potential $(\mu)$, electronegativity $(\chi)$, chemical hardness $(\eta)$, electrophilicity $(\omega)$, and softness (S) were calculated according to the literature (Karelson et al., 1996; Rajan et al., 2017) and the results are given in Table 1. Bergaptol has lower values for ionization potential than xanthotoxol. Hardness describes the stability of the electron cloud of a molecule and therefore the lower value of this parameter would be present in more reactive species. This is also proven in this study, as the lowest $\eta$ is calculated for bergaptol. Electronegativity is the lower for bergaptol and it is important because this parameter explains the reactivity of a molecule. The chemical potential has the same value as electronegativity just without a minus sign, therefore it describes the resistivity of the molecule towards free radicals. Electrophilicity of a molecule is also a measure of reactivity because it describes the capacity of the system to acquire an electron (Wang et al., 2019). This value is the same for both molecules. The overall conclusion from the analysis of reactivity parameters is that bergaptol can be considered as a more reactive molecule than xanthotoxol.

\begin{tabular}{ccccccccc}
\hline Compounds & $\begin{array}{l}\text { Gap } \\
(\mathbf{e V})\end{array}$ & $\mathbf{I}$ & $\mathbf{A}$ & $\boldsymbol{\mu}(\mathbf{e V})$ & $\chi(\mathbf{e V})$ & $\begin{array}{c}\boldsymbol{\eta} \\
(\mathbf{e V})\end{array}$ & $\boldsymbol{\omega}(\mathbf{e V})$ & $\begin{array}{c}\mathbf{S} \\
\left(\mathbf{e V}^{-1}\right)\end{array}$ \\
\hline BER & 6.26 & 7.53 & 1.27 & -4.40 & 4.40 & 3.13 & 1.55 & 1.57 \\
XAN & 6.32 & 7.59 & 1.27 & -4.43 & 4.43 & 3.16 & 1.55 & 1.58 \\
\hline
\end{tabular}

Table 1. Global reactivity parameters for the investigated compounds (calculated at M06-2X/6$311++\mathrm{G}(\mathrm{d}, \mathrm{p})$ level of theory)

\subsection{Radicals, radical cations, and anions of investigated compounds}

The homolytic cleavage of the $\mathrm{O}-\mathrm{H}$ bonds in the investigated compounds leads to the formation of two radicals (Fig. S1). The corresponding BDE values are given in Table 2. The BDE values for bergaptol, in both solvents, are lower than xanthotoxol.

The stability and reactivity of both formed radicals were examined by the natural spin densities as they successfully represent electron delocalization (Marković et al., 2011). The unpaired electron is mainly delocalized over the oxygen which suffered hydrogen abstraction, and ortho and para carbon atoms (O5, C6, C8, C10 and in BER-R; O9, C8, C10, and C5 in XAN-R) and that is shown on the Fig 4. The spin density value on O5 in BER-R is smaller than the values on $\mathrm{O} 8$ in the $\mathrm{XAN}-\mathrm{R}$. In addition, the unpaired electron in both radicals was delocalized via the carbon of the furan ring ( $\mathrm{C} 2$ ' in BER-R and $\mathrm{C} 1$ ' in $\mathrm{XAN}-\mathrm{R}$ radical).

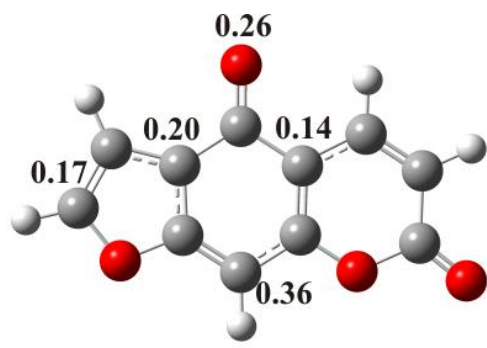

BER-R

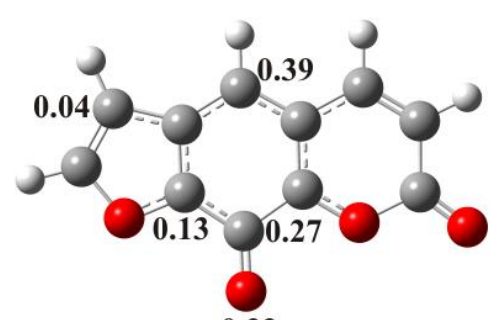

0.32

XAN-R

Fig. 4. The optimized structure of bergaptol (left) and xanthotoxol (right) radicals in water with natural spin densities values 


\begin{tabular}{|c|c|c|c|c|c|c|}
\hline \multirow{3}{*}{ Compounds } & \multirow{3}{*}{ Position } & \multicolumn{5}{|c|}{ Benzene, $\varepsilon=2.27$} \\
\hline & & \multirow{2}{*}{$\begin{array}{l}\text { HAT } \\
\text { BDE }\end{array}$} & \multicolumn{2}{|c|}{ SET-PT } & \multicolumn{2}{|c|}{ SPLET } \\
\hline & & & IP & PDE & $\mathrm{PA}$ & ETE \\
\hline BER & $5-\mathrm{OH}$ & 332 & 666 & 99 & 375 & 390 \\
\hline XAN & $8-\mathrm{OH}$ & 357 & 671 & 119 & 427 & 363 \\
\hline \multirow{3}{*}{ Compounds } & \multirow{3}{*}{ Position } & \multicolumn{5}{|c|}{ Water, $\varepsilon=78.35$} \\
\hline & & HAT & \multicolumn{2}{|c|}{ SET-PT } & \multicolumn{2}{|c|}{ SPLET } \\
\hline & & $\mathrm{BDE}$ & IP & PDE & PA & ETE \\
\hline BER & $5-\mathrm{OH}$ & 334 & 490 & 44 & 169 & 365 \\
\hline XAN & $8-\mathrm{OH}$ & 347 & 497 & 50 & 198 & 349 \\
\hline
\end{tabular}

Table 2. Calculated thermodynamic parameters of mechanisms of antioxidant activity (kJ mol${ }^{1}$ ) of BER and XAN in benzene and water

By an electron loss investigation, compounds yield the corresponding radical cations. The IP values for both compounds in all solvents are presented in Table 2. The IP values of BER and XAN in benzene are higher, while in water are lower than to those of caffeic acid $(572.2$ and $\left.664.2 \mathrm{~kJ} \mathrm{~mol}^{-1}\right)$, cyanidin $\left(583.7\right.$ and $\left.797.7 \mathrm{~kJ} \mathrm{~mol}^{-1}\right)$, epicatechin $(540.9$ and $634.6 \mathrm{~kJ}$ $\mathrm{mol}^{-1}$ ), and resveratrol (519.6 and $592.0 \mathrm{~kJ} \mathrm{~mol}^{-1}$ ) (Leopoldini et. al., 2004).

The IP values of investigated compounds in the polar solvent are significantly lower than the value in the nonpolar solvent. This finding is a consequence of the stabilization of the radical cation in the polar solvents. Our investigation shows that the spin density and the positive charge of the radical cations of investigated compounds are delocalized over the benzene ring and carbon atoms of furan rings (Fig. 5). The highest spin density and positive charge values of BER and XAN are located on C5 and C8, respectively. This suggests that proton transfer is slightly easier from the 5-OH of bergaptole than from $8-\mathrm{OH}$ of xanthotoxol. This fact is supported by the PDE values (Table 2), since the smallest PDE value, in both solvents, corresponds to bergaptol.



BER-RC

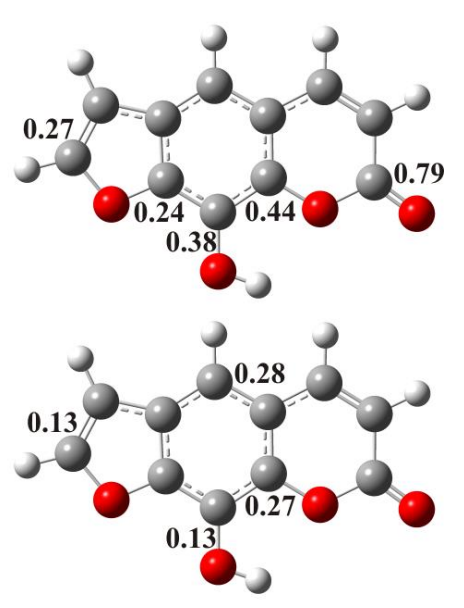

XAN-RC

Fig. 5. The optimized structure of bergaptol (left) and xanthotoxol (right) radical cations in water with natural spin (above) and charge (down) distribution

The calculated PA values of both $\mathrm{OH}$ groups of investigated compounds are given in Table 2. In both solvents, the PA values are lower for the 5-OH group of bergaptole, indicating that proton transfer from this group is easier than from the 8-OH of xantoxahol. Significantly lower 
PA values in polar solvents are a consequence of the interactions of $\mathrm{OH}$ groups and anions with the solvent molecules. The electron charge density of all anions is presented in Fig. 6. In BERA the negative charge is delocalized over $\mathrm{O5}, \mathrm{C} 10, \mathrm{C} 6, \mathrm{C} 8$ on benzene ring and $\mathrm{C} 1$ ' atoms of the furan ring, which contributes to the stability of the anion. On the other hand, in XAN-A the negative charge is delocalized over $\mathrm{O} 8, \mathrm{C} 10, \mathrm{C} 5, \mathrm{C} 6$ of the benzene ring and $\mathrm{C} 1$ ' atom of the furan ring. The spin density value indicates that the negative charge on $\mathrm{O} 8(-0.84 e)$ atom in the $\mathrm{XAN}-\mathrm{A}$ higher than $\mathrm{O} 5(-0.80 e)$ atom in BER-A.

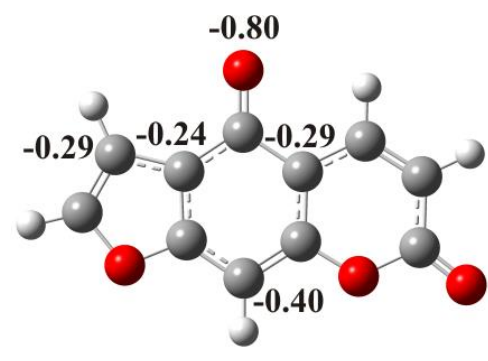

BER-A

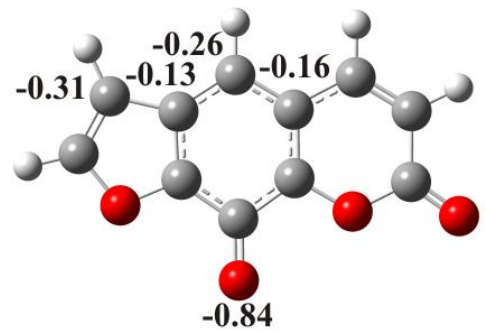

XAN-A

Fig. 6. The optimized structure of bergaptol (left) and xanthotoxol (right) anions with values of natural charge distribution

\subsection{Free radical scavenging mechanisms of investigated compounds}

Reaction enthalpies related to three mechanisms of free radical scavenging activity of bergaptol and xanthoxaol (HAT, SET-PT, and SPLET) were calculated according to equations listed above (11-15). The privileged mechanism of the antioxidant activity is estimated based on the BDE, IP, and PA values. The lowest of these values shows which mechanism of antiradical action is thermodynamically more favorable. One of the prerequisites for an investigated compound to be an antioxidant is stable radical that is formed after scavenging. From results presened in Table 2, it is clear that in water, PAs values of examined compounds are significantly lower than the corresponding BDE and IP values. This indicates that the SPLET mechanism represents the most probable reaction pathway of antioxidant action in polar media. In nonpolar solvent, benzene, the estimated BDE and PA values are significantly lower than than the corresponding BDE and IP values. However, the ETE values describing the second step of the SPLET mechanism are significantly large. This indicates that the HAT mechanism represents the most probable reaction pathway in the nonpolar solvent. From the significantly higher values for IP, in both solvents, it can be concluded that SET-PT is not an operational mechanism. If we compared the reactivity of the investigated compounds, it can be concluded that a higher free radical scavenging potency has BER.

\subsection{Antioxidant activity of investigated compounds with different reactive oxygen species}

Gibss free energies of BER and XAN with the different reactive oxygen species: hydroxy $(\mathbf{O H})$, hydroperoxy $(\mathbf{O O H})$, methoxy $\left(\mathrm{OCH}_{3}\right)$, methyl peroxy $\left(\mathrm{OOCH}_{3}\right)$, vinil peroxy $\left(\mathbf{O O C H C H}_{2}\right)$, iso-propoxy $\left({ }^{\circ} \mathrm{OCH}\left(\mathrm{CH}_{3}\right)_{2}\right)$, who are related to three mechanisms of free radical scavenging activity (HAT, SET-PT, and SPLET) are presented in Table 3.

The preferred mechanism of the antiradical activity of investigated compounds can be estimated from $\Delta_{\mathrm{r}} \mathrm{G}_{\mathrm{BDE}}, \Delta_{\mathrm{r}} \mathrm{G}_{\mathrm{IP}}$, and $\Delta_{\mathrm{r}} \mathrm{G}_{\mathrm{PA}}$ values. Namely, the lowest of these values indicate which mechanism of antiradical action is favorable. 


\begin{tabular}{|c|c|c|c|c|c|c|c|c|c|c|c|c|}
\hline \multirow{3}{*}{ Radicals } & \multirow{3}{*}{ Compounds } & \multirow{3}{*}{ Position } & \multicolumn{5}{|c|}{ Benzene, $\varepsilon=2.27$} & \multicolumn{5}{|c|}{ Water, $\varepsilon=78.35$} \\
\hline & & & \multirow{2}{*}{$\begin{array}{c}\text { HAT } \\
\text { BDE }\end{array}$} & \multicolumn{2}{|c|}{ SET-PT } & \multicolumn{2}{|c|}{ SPLET } & \multirow{2}{*}{$\begin{array}{l}\text { HAT } \\
\text { BDE }\end{array}$} & \multicolumn{2}{|c|}{ SET-PT } & \multicolumn{2}{|c|}{ SPLET } \\
\hline & & & & IP & PDE & PA & ETE & & IP & PDE & PA & ETE \\
\hline \multirow{2}{*}{ OH } & BER & $5-\mathrm{OH}$ & -162 & 334 & -495 & -221 & 59 & -163 & 112 & -276 & -150 & -14 \\
\hline & XAN & $8-\mathrm{OH}$ & -137 & 340 & -478 & -170 & 32 & -150 & 118 & -269 & -121 & -30 \\
\hline \multirow{2}{*}{ ООН } & BER & $5-\mathrm{OH}$ & -28 & 409 & -437 & -162 & 135 & -28 & 200 & -228 & -102 & 74 \\
\hline & XAN & $8-\mathrm{OH}$ & -4 & 416 & -419 & -111 & 108 & -15 & 206 & -221 & -73 & 58 \\
\hline \multirow{2}{*}{$\mathrm{OCH}_{3}$} & BER & $5-\mathrm{OH}$ & -100 & 377 & -477 & -202 & 102 & -100 & 173 & -273 & -147 & 47 \\
\hline & XAN & $8-\mathrm{OH}$ & -75 & 383 & -459 & -151 & 75 & -87 & 179 & -266 & -118 & 31 \\
\hline \multirow{2}{*}{$\mathrm{OOCH}_{3}$} & BER & $5-\mathrm{OH}$ & -19 & 414 & -433 & -158 & 139 & -18 & 209 & -228 & -102 & 83 \\
\hline & XAN & $8-\mathrm{OH}$ & 5 & 420 & -415 & -107 & 112 & -6 & 215 & -221 & -73 & 67 \\
\hline \multirow{2}{*}{$\mathrm{OOCHCH}_{2}$} & BER & $5-\mathrm{OH}$ & -26 & 365 & -391 & -116 & 90 & -26 & 172 & -199 & -73 & 46 \\
\hline & XAN & $8-\mathrm{OH}$ & -2 & 371 & -373 & -65 & 63 & -14 & 178 & -192 & -44 & 30 \\
\hline \multirow{2}{*}{$\mathrm{OCH}\left(\mathrm{CH}_{3}\right)_{2}$} & BER & $5-\mathrm{OH}$ & -104 & 364 & -468 & -193 & 90 & -103 & 170 & -273 & -147 & 44 \\
\hline & XAN & $8-\mathrm{OH}$ & -79 & 371 & -450 & $\overline{-142}$ & 63 & $\begin{array}{c}-93 \\
\end{array}$ & 176 & -266 & -118 & 28 \\
\hline
\end{tabular}

Table 3. Calculated thermodynamic parameters of mechanisms of antioxidant activity $\left(\mathrm{kJ} \mathrm{mol}^{-}\right.$

${ }^{1}$ ) of BER and XAN with different reactive oxygen species in benzene and water

In benzene, the $\Delta_{\mathrm{r}} G_{\mathrm{BDE}}$ and $\Delta_{\mathrm{r}} G_{\mathrm{PA}}$ values indicate that reactions with all radicals are exergonic, except in the case of $\Delta_{\mathrm{r}} G_{\mathrm{BDE}}$ for reaction with a $\mathbf{O O C H}_{3}$ radical that is slightly endergonic $\left(5 \mathrm{~kJ} \mathrm{~mol}^{-1}\right)$. Although the $\Delta_{\mathrm{r}} G_{\mathrm{PA}}$ values are exergonic, the energies $\Delta_{\mathrm{r}} G_{\mathrm{ETE}}$ who describing the second step of SPLET is significantly endergonic. For this reason, it can be concluded that in benzene the HAT is a preferred mechanism of the antiradical activity.

In the aqueous medium, the $\Delta_{\mathrm{r}} G_{\mathrm{BDE}}$ and $\Delta_{\mathrm{r}} G_{\mathrm{PA}}$ values indicate that reactions with all radicals are exergonic. While the $\Delta_{\mathrm{r}} G_{\mathrm{BDE}}$ values are similar to those in benzene, the $\Delta_{\mathrm{r}} G_{\mathrm{PA}}$ values in water are significantly lower. It is well known that when reactants or products are ionic species, the polarity of the solvent has a significant effect on the reaction course. Consequently, it is clear why the $\Delta_{\mathrm{r}} G_{\mathrm{BDE}}$ values are almost constant for certain radicals in all solvents under investigation, while $\Delta_{\mathrm{r}} G_{\mathrm{PA}}$ is not. The first step of the SPLET mechanism decreases the solvent polarity results in less stability of the reactants and leads to the $\Delta_{\mathrm{r}} G_{\mathrm{PA}}$ decrease. The negative values of $\Delta_{\mathrm{r}} G_{\text {ETE }}$ for the reaction BER and XAN with the $\mathbf{O H}$ radical (14 and $-30 \mathrm{~kJ} \mathrm{~mol}^{-1}$, respectively), as well as $\Delta_{\mathrm{r}} G_{\mathrm{ETE}} \leq 30 \mathrm{~kJ} \mathrm{~mol}^{-1}$ in the rection XAN with $\mathbf{O C H}_{3}, \mathbf{O O C H C H}_{2}, \mathbf{O C H}\left(\mathbf{C H}_{3}\right)_{2}$ radicals $\left(31,30\right.$ and $28 \mathrm{~kJ} \mathrm{~mol}^{-1}$ respectively), indicate that SPLET and HAT mechanisms, in this case, are competitive. In reaction with other radicals in water, the HAT mechanism of antiradical action is dominant.

Expectedly, based on a previous discussion of thermodynamic parameters, BER shows a better ability to purify reactive radical species. Based on the results from Table 2, it can be concluded that in both solvents, the reactivity of the examined compounds to the reactive oxygen species decreases in sequence $\mathrm{OH}>{ }^{\circ} \mathrm{OCH}_{3}>\mathrm{OCH}\left(\mathrm{CH}_{3}\right)_{2}>\mathrm{OOH}>{ }^{\circ} \mathrm{OOCHCH}_{2}>$ OOCH3. The $\Delta_{\mathrm{r}} G_{\mathrm{IP}}$ values reveal that SET-PT is not an operative antioxidant mechanism under these conditions. Moreover, the stability of the radical cation decreases with the decreasing solvent polarity. 


\subsection{Molecular docking simulation}

Estrogen receptor alpha $(\mathbf{E R \alpha})$ is nuclear of the estrogen receptor that is activated by the sex hormone estrogen. ER $\boldsymbol{\alpha}$ has important physiological functions in different organ systems including the reproductive, central nervous, skeletal, and cardiovascular systems (Katzenellenbogen et al., 2000). For this reason, this receptor is widely distributed in the human body, including the female reproductive organs (uterus and ovary), male reproductive organs, mammary glands, hypothalamus, heart, kidney, spleen, pituitary gland, liver, lung, bone, and adipose tissue. In addition to the wide role and prevalence in important physiological processes, estrogen is also involved in the development and progression of various diseases, including various cancers (breast, ovarian, colorectal), prostate, endometrium, osteoporosis, neurodegenerative diseases, cardiovascular diseases, insulin resistance, lupus erythematosus, endometriosis, and obesity. In these abnormalities, estrogen mediates its effects through the estrogen receptor, which is the basis for many therapeutic interventions (Jia et al.,2015).

To predict the inhibitory effect of the investigated compounds according to the ER $\boldsymbol{\alpha}$ receptor the molecular docking study was applied. Based on the previously discussed values, it was concluded that the first step of the SPLET mechanism, the deprotonation process, is thermodynamically favorable. For this reason, a molecular docking study was also performed with the corresponding anionic species.

The potential ligand binding sites, as well as important thermodynamic parameters of protein-ligand complex, were determined from this study. The thermodynamic parameters obtained after the molecular docking simulation are free energy of binding $\left(\Delta \mathrm{G}_{\text {bind }}\right)$ and constant of inhibition $\left(\mathrm{K}_{\mathrm{i}}\right)$. Additionally, the free energy of binding involves different contributions such as final total internal energy $\left(\Delta \mathrm{G}_{\text {total }}\right)$, torsional free energy $\left(\Delta \mathrm{G}_{\mathrm{tor}}\right)$, unbound system's energy $\left(\Delta \mathrm{G}_{\mathrm{unb}}\right)$, electrostatic energy $\left(\Delta \mathrm{G}_{\mathrm{elec}}\right)$ and the sum of dispersion and repulsion $\left(\Delta \mathrm{G}_{\mathrm{vdw}}\right)$, hydrogen bond $\left(\Delta \mathrm{G}_{\text {hbond }}\right)$ and desolvation $\left(\Delta \mathrm{G}_{\text {desolv }}\right)$. These values can help in a better understanding of the binding mode of the investigated compound in the active site of the receptor. The importance of these parameters is described in detail in the previous research (Avdović et al., 2020).

\begin{tabular}{|c|c|c|c|c|c|c|c|c|}
\hline $\begin{array}{c}\text { Conformation } \\
\text { s }\end{array}$ & $\begin{array}{c}\Delta \mathbf{G}_{\text {bind }} \\
\mathrm{kJ} \mathrm{mol}^{-1}\end{array}$ & $\begin{array}{c}\mathbf{K}_{\mathrm{i}} \\
(\mu \mathrm{M})\end{array}$ & $\begin{array}{c}\Delta \mathbf{G}_{\text {inter }} \\
\mathrm{kJ} \mathrm{mol}^{-1}\end{array}$ & $\begin{array}{c}\Delta \mathbf{G}_{v d w+h b o n d+d e s o l v} \\
\mathrm{~kJ} \mathrm{~mol}^{-1}\end{array}$ & $\begin{array}{c}\Delta \mathbf{G}_{\text {elec }} \\
\mathrm{kJ} \mathrm{mol}^{-1}\end{array}$ & $\begin{array}{c}\Delta \mathbf{G}_{\text {total }} \\
\mathrm{kJ} \mathrm{mol}^{-1}\end{array}$ & $\begin{array}{c}\Delta \mathbf{G}_{t o r} \\
\mathrm{~kJ} \mathrm{~mol}^{-1}\end{array}$ & $\begin{array}{c}\Delta \mathbf{G}_{\text {unb }} \\
\mathrm{kJ} \mathrm{mol}^{-1}\end{array}$ \\
\hline ER $\alpha$-BER & -29.7 & 6.4 & -30.9 & -29.5 & -1.3 & 0.3 & 1.3 & 0.3 \\
\hline ER $\alpha$-BER-A & -28.7 & 9.6 & -28.7 & -27.9 & -0.7 & 0.0 & 0.0 & 0.0 \\
\hline ERo-XAN & -27.8 & 13.4 & -29.1 & -27.7 & -1.4 & -3.0 & 1.3 & -3.0 \\
\hline ERo-XAN-A & -27.6 & 6.6 & -29.1 & -27.8 & -1.8 & 0.0 & 0.0 & 0.0 \\
\hline
\end{tabular}

Table 4. Important thermodynamic parameters obtained after molecular docking simulation

If one compared the most stable conformations of investigated species in the active site of the receptor, the binding affinity decreases in sequence ER $\boldsymbol{\alpha}$-BER $>$ ER $\boldsymbol{\alpha}$-BER-A $>$ ER $\boldsymbol{\alpha}$-XAN $>\mathbf{E R} \boldsymbol{\alpha}-\mathbf{X A N}-\mathbf{A}$. The best confirmation of the investigated compound, ERo-BER, have the most negative value for the free energy of binding $\left(-29.7 \mathrm{~kJ} \mathrm{~mol}^{-1}\right)$ and the lowest value for the constant of inhibition $(6.4 \mu \mathrm{M})$. Both compounds in their neutral form show a better inhibitory effect than the corresponding anionic species. This means that the $\mathrm{OH}$ group contributes to the stability of the protein-ligand complex. The neutral and anionic forms of BER show a better inhibitory effect against the $\mathrm{ER} \alpha$ receptor. This means that the $\mathrm{OH}$ group at position 5 of the psoralen ring contributes to a better inhibitory effect. Besides, results presented in Table 4 shows clearly that the greatest contribution to $\Delta \mathrm{G}_{\text {bind }}$, for all structures, comes from the sum of $\Delta \mathrm{G}_{\mathrm{vdw}+\mathrm{hbond+desolv}}$. In addition, the values for $\Delta \mathrm{G}_{\text {total }}, \Delta \mathrm{G}_{\mathrm{tor}}, \Delta \mathrm{G}_{\mathrm{unb}}$ in complexes ER $\boldsymbol{\alpha}$-BER-A and ERo-XAN-A are $0.0 \mathrm{~kJ} \mathrm{~mol}^{-1}$ because of the rigidity of anionic species. 
The most stable docking structures of neutral and anionic species into ER $\boldsymbol{\alpha}$ receptor are presented at Figure 7, while results collected in Table 5 represent the type of interactions and corresponding distances.

\begin{tabular}{|c|c|c|c|c|c|}
\hline \multicolumn{3}{|c|}{ ER $\alpha$-BER } & \multicolumn{3}{|c|}{ ER $\alpha$-BER-A } \\
\hline Interactions: & Types of interactions: & $\AA$ & Interactions: & Types of interactions: & $\AA$ \\
\hline $\begin{array}{c}\text { LEU327:HN- } \\
\text { BER:O }\end{array}$ & $\begin{array}{c}\text { Conventional } \\
\text { Hydrogen Bond }\end{array}$ & 1.90 & $\begin{array}{c}\text { LEU327:HN - BER- } \\
\text { A:O }\end{array}$ & $\begin{array}{c}\text { Conventional } \\
\text { Hydrogen Bond }\end{array}$ & 1.96 \\
\hline BER:H - GLU353:O & $\begin{array}{c}\text { Conventional } \\
\text { Hydrogen Bond }\end{array}$ & 1.71 & ILE326:C - BER-A:O & $\begin{array}{c}\text { Carbon Hydrogen } \\
\text { Bond }\end{array}$ & 3.17 \\
\hline ILE326:C - BER:O & $\begin{array}{c}\text { Carbon Hydrogen } \\
\text { Bond }\end{array}$ & 3.10 & LYS449:H - BER-A & Pi-Cation & 2.78 \\
\hline GLU353:O - BER & Pi-Anion & 2.97 & GLU353:O - BER-A & Pi-Anion & 3.04 \\
\hline A:TRP360 - BER & Pi-Pi T-shaped & 5.09 & TRP360 - BER-A & Pi-Pi T-shaped & 5.16 \\
\hline BER - TRP360 & Pi-Pi T-shaped & 5.05 & BER-A - TRP360 & Pi-Pi T-shaped & 5.12 \\
\hline BER - PRO324 & Pi-Alkyl & 3.63 & BER-A - PRO324 & Pi-Alkyl & 3.84 \\
\hline BER - PRO324 & Pi-Alkyl & 3.83 & BER-A - PRO324 & Pi-Alkyl & 3.62 \\
\hline BER - PRO324 & Pi-Alkyl & 4.74 & BER-A - PRO324 & Pi-Alkyl & 4.17 \\
\hline BER - MET357 & Pi-Alkyl & 4.66 & BER-A - MET357 & Pi-Alkyl & 4.43 \\
\hline \multicolumn{3}{|c|}{ ERa-XAN } & \multicolumn{3}{|c|}{ ERo-XAN-A } \\
\hline $\begin{array}{c}\text { LEU327:HN - } \\
\text { XAN:O }\end{array}$ & $\begin{array}{c}\text { Conventional } \\
\text { Hydrogen Bond }\end{array}$ & 2.02 & LYS449:H - XAN-A:O & $\begin{array}{c}\text { Conventional } \\
\text { Hydrogen Bond }\end{array}$ & 1.90 \\
\hline LYS449:H - XAN:O & $\begin{array}{c}\text { Conventional } \\
\text { Hydrogen Bond }\end{array}$ & 1.88 & LYS449:H - XAN-A:O & $\begin{array}{c}\text { Conventional } \\
\text { Hydrogen Bond }\end{array}$ & 2.19 \\
\hline ILE326:C- XAN:O & $\begin{array}{c}\text { Carbon Hydrogen } \\
\text { Bond } \\
\end{array}$ & 3.24 & GLY390:C - XAN-A:O & $\begin{array}{c}\text { Carbon Hydrogen } \\
\text { Bond } \\
\end{array}$ & 3.67 \\
\hline GLU353:O - :XAN & Pi-Anion & 3.15 & ARG394:NH - XAN-A & Pi-Cation & 3.30 \\
\hline TRP360 - :XAN & Pi-Pi T-shaped & 4.74 & TRP360-XAN-A & Pi-Pi T-shaped & 5.73 \\
\hline XAN - TRP360 & Pi-Pi T-shaped & 4.69 & TRP360-XAN-A & Pi-Pi T-shaped & 5.88 \\
\hline XAN - PRO324 & Pi-Alkyl & 3.49 & XAN-A - PRO324 & Alkyl & 4.08 \\
\hline XAN - PRO324 & Pi-Alkyl & 3.80 & XAN-A - PRO324 & Pi-Alkyl & 3.57 \\
\hline XAN - PRO324 & Pi-Alkyl & 4.52 & \multirow{2}{*}{ XAN-A - ILE326 } & \multirow{2}{*}{ Pi-Alkyl } & \multirow{2}{*}{4.60} \\
\hline XAN - MET357 & Pi-Alkyl & 3.15 & & & \\
\hline
\end{tabular}

Table 5. Types of interactions and corresponding distances obtained after molecular docking simulation

By analyzing the most stable conformations of BER and BER-A in the ER $\boldsymbol{\alpha}$ receptor, it can be concluded that the tested species are surrounded by identical amino acid residues. Despite the polar oxygen atoms, there is a small number of hydrogen bonds that are most significant in the interpretation of protein-ligand interactions.

In the ERa-BER protein-ligand complex, the amino acid GLU 353 establishes a conventional hydrogen bond via an oxygen atom of the carbonyl group to the hydrogen atom of the $\mathrm{OH}$ group of BER (1.71 $\mathrm{A})$. This contact in the ER $\boldsymbol{\alpha}$-BER-A complex was missing. In addition, in ERo-BER and ERo-BER-A complexes the amino acid LEU 327, via the NH group, forms a hydrogen bond with the carbonyl oxygen of the lactone ring with different distances. An interesting carbon hydrogen bond is formed between amino acid ILE 326 and the oxygen atom of the lactone ring of BER and XAN. In addition, the amino acid GLU 353 forms an electrostatic $\pi$-anion interaction, through a partial negative oxygen atom $\left(\mathrm{O}^{-}\right)$of the carbonyl group with the chroman ring of investigated compounds. Additionally, in the ERo-BER-A complex, amino acid LYS 449, via a partially positive $\mathrm{NH}^{+}$group, establishes an electrostatic $\pi$ cation interaction with the aromatic furan ring. In both complexes, the most common type of interactions are hydrophobic interactions. Furan ring of investigated compounds establishes weak $\pi-\pi$-T contacts with the aromatic indole ring of the amino acid TRP 360 . Shorter and 
slightly stronger domain $\pi$-alkyl contacts are established between aromatic and partial aromatic rings of investigated compounds and amino acid PRO 324.

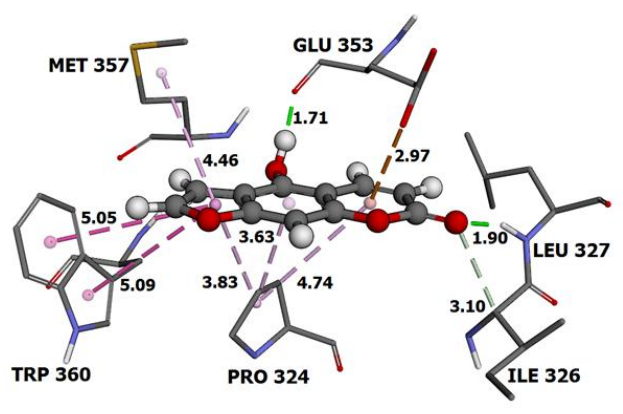

ERo-BER

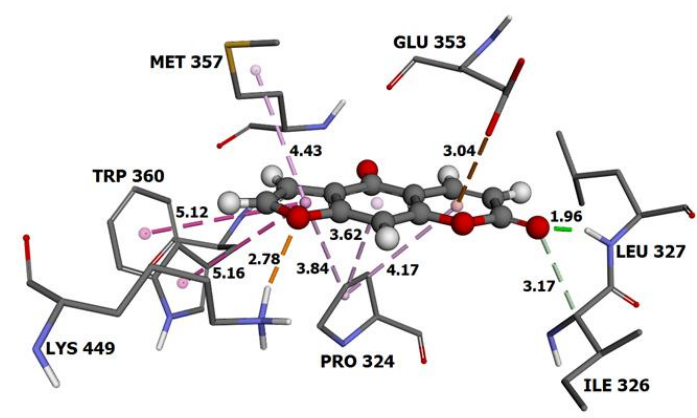

ER $\alpha$-BER-A

Fig.7. The most stable docking structures of BER and BER-A into ERa

On the other hand, in ERo-XAN and ERo-XAN-A complexes (Fig.8) amino acids LEU 327 and LYS 449, via hydrogen atom of NH group, establish hydrogen bond with the oxygen atom of chroman and furan ring, respectively. Hydrogen bond furcation is a ubiquitous phenomenon in macromolecular structures. A donor can interact with several acceptors simultaneously or an acceptor can interact simultaneously with many donors. The terms bifurcated and trifurcated are commonly used to describe these arrangements. The amino acid LYS 449 across hydrogen atoms of $-\mathrm{NH}_{2}$ groups, build bifurcated geometry with oxygen atoms O1 (1.90 $)$ ) and O9 (2.90 $\AA$ ) of pyron ring of XAN-A. The amino acid ILE 326 in ER $\boldsymbol{\alpha}$-XAN and GLY 390 in ERo-XAN-A establish carbon hydrogen bond with O1 atom of chroman ring and $\mathrm{O} 9$ atom of the aromatic ring, respectively. In this case, electrostatic interactions contribute to the total binding energy. In ERo-XAN complex amino acid GLU 353 establish $\pi$-cation interaction with partial aromatic lactone ring, while amino acid ARG 394 in ERo-XAN-A formed $\pi$-anion interaction with aromatic furan ring. Besides, aromatic rings of investigated compounds in both complexes are included in the stabilization by hydrophobic $\pi$-alkyl and $\pi$ - $\pi$ T interactions with amino acids PRO 324, TRP 326, MET 357, LYS 449.



$\mathbf{E R} \alpha-\mathrm{XAN}$

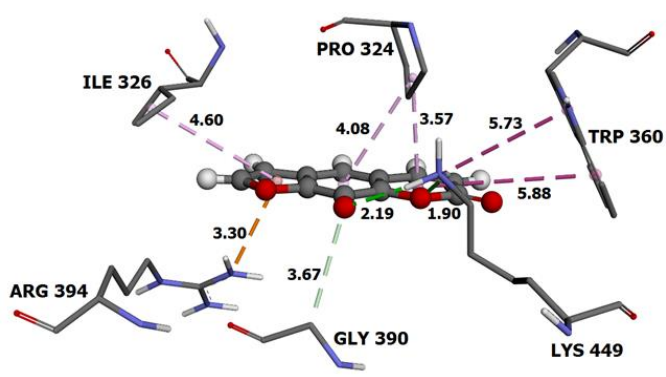

ERo-XAN-A

Fig. 8. The most stable docking structures of XAN and XAN-A into ERa 


\section{Conclusions}

Based on the calculated thermodynamic parameters, we conclude the examined compounds exhibit antioxidant properties through the HAT mechanism that in benzene. In water, a competition between the HAT and SPLET mechanisms of antioxidant action is present in both investigated compunds. Inactivation of ROS with reactive oxygen species (ROS), the possibility and manner of elimination depend on the reactivity of the oxygen species and of the type of solvent. The ability to remove radicals has been shown to decrease in the series ${ }^{\circ} \mathbf{O H}>{ }^{\cdot} \mathbf{O C H} \mathbf{C H}_{3}$ $\cdot \mathrm{OCH}\left(\mathrm{CH}_{3}\right)_{2}>\mathrm{OOH}>\mathrm{OOCHCH}_{2}>\mathrm{OOCH}_{3}$. It also can be concluded that, in both solvents, bergaptol exhibits better antioxidant properties than xanthotoxol. This is due to the stabilization by hydrogen bond in the xanthotoxol structure. The molecular docking simulation results indicate that the neutral forms of both compounds show a better inhibitory effect than the corresponding anionic species. On the other hand, both investigation bergaptol forms (neutral and anionic) show slightly higher inhibitory activity toward the ER $\alpha$ receptor than xanthotoxol. In summary, the $\mathrm{OH}$ group at position 5 has a more significant effect on the antioxidant and biological properties of bergaptol then $\mathrm{OH}$ group at position 8 of xanthotoxol.

Acknowledgments: This work was supported by the Serbian Ministry of Education, Science and Technological Development (Agreements No. 451-03-68/2020-14/200122; 451-0368/2020-14/200378).

\section{References}

Apel K., Hirt H. (2004). Reactive oxygen species: metabolism, oxidative stress, and signal transduction. Annual Review of Plant Biology, 55, 373-399.

Avdović E. H, Milanović Ž. B, Živanović M. N, Šeklić D. S, Radojević I. D, Čomić L. R, Marković Z. S. (2020). Synthesis, spectroscopic characterization, biological activity, DFT and molecular docking study of novel 4-hydroxycoumarine derivatives and corresponding palladium (II) complexes. Inorganica Chimica Acta, 504, 119465.

Bian S, Jiang Y. (2009). Reactive oxygen species, antioxidant enzyme activities and gene expression patterns in leaves and roots of Kentucky bluegrass in response to drought stress and recovery. Scientia Horticulturae, 120(2), 264-270.

Devienne K. F, Cálgaro-Helena A. F, Dorta D J., Prado I. M, Raddi M. S. G, Vilegas W, Curti C. (2007). Antioxidant activity of isocoumarins isolated from Paepalanthus bromelioides on mitochondria. Phytochemistry, 68(7), 1075-1080.

Dimić D, Milenković D, Dimitrić Marković J, Marković Z. (2017). Antiradical activity of catecholamines and metabolites of dopamine: Theoretical and experimental study. Physical Chemistry Chemical Physics, 19(20), 12970-12980.

Đorović J, Marković J. M. D, Stepanić V, Begović N, Amić D, Marković Z. (2014). Influence of different free radicals on scavenging potency of gallic acid. Journal of molecular modeling, 20(7), 2345.

Frisch M. J, Trucks G. W, Schlegel H. B, Scuseria G. E, Robb M. A, Cheeseman J. R, Millam J. M. (2003). Revision B. Gaussian. Inc., Pittsburgh PA.

Gfeller D, Grosdidier A, Wirth M, Daina A, Michielin O, Zoete V. (2014). SwissTargetPrediction: a web server for target prediction of bioactive small molecules. Nucleic acids research, 42(W1), W32-W38.

Girennavar B, Jayaprakasha G. K, Jadegoud Y, Gowda G. N, Patil B. S. (2007). Radical scavenging and cytochrome P450 3A4 inhibitory activity of bergaptol and geranylcoumarin from grapefruit. Bioorganic \& medicinal chemistry, 15(11), 3684-3691. 
Jia M, Dahlman-Wright K, Gustafsson J A. (2015). Estrogen receptor alpha and beta in health and disease. Best practice \& research Clinical endocrinology \& metabolism, 29 (4), 557568.

Karelson M, Lobanov V. S, Katritzky A. R. (1996). Quantum-Chemical Descriptors in QSAR/QSPR Studies. Chemical Reviews, 96(3), 1027-1044.

Katzenellenbogen B. S, Katzenellenbogen J. A. (2000). Estrogen receptor transcription and transactivation Estrogen receptor alpha and estrogen receptor beta: regulation by selective estrogen receptor modulators and importance in breast cancer. Breast Cancer Research, $2(5), 335$.

Klein E, Lukeš V, Ilčin M. (2007). DFT/B3LYP study of tocopherols and chromans antioxidant action energetics. Chemical physics, 336(1), 51-57.

Kostova I, Bhatia S, Grigorov P, Balkansky S. S, Parmar V, K Prasad, A, Saso L. (2011). Coumarins as antioxidants. Current medicinal chemistry, 18(25), 3929-3951.

Leopoldini M, Marino T, Russo N, Toscano M. (2004). Antioxidant properties of phenolic compounds: H-atom versus electron transfer mechanism. The Journal of Physical Chemistry A, 108(22), 4916-4922.

Liou G. Y, Storz P. (2010). Reactive oxygen species in cancer. Free radical research, 44(5), 479-496.

Marković Z. S, Dimitrić-Marković J. M, Milenković D, Filipović N. (2011). Structural and electronic features of baicalein and its radicals. Monatshefte für Chemie-Chemical Monthly, 142(2), 145-152.

Morris G. M, Huey R, Lindstrom W, Sanner M. F, Belew R. K, Goodsell D. S, Olson A. J. (2009). AutoDock4 and AutoDockTools4: Automated docking with selective receptor flexibility. Journal of computational chemistry, 30(16), 2785-2791.

Pathak M. A, Daniels Jr F, Fitzpatrick T. B. (1962). The presently known distribution of furocoumarins (psoralens) in plants. Journal of investigative Dermatology, 39(3), 225-239.

Rajan V. K, Muraleedharan K. (2017). A computational investigation on the structure, global parameters and antioxidant capacity of a polyphenol, Gallic acid. Food Chemistry, 220, 93-99.

Shahidi F, Janitha P. K, Wanasundara P. D. (1992). Phenolic antioxidants. Critical reviews in food science \& nutrition, 32(1), 67-103.

Shiau A. K, Barstad D, Loria P. M, Cheng L, Kushner P. J, Agard D. A, Greene, G. L. (1998). The structural basis of estrogen receptor/coactivator recognition and the antagonism of this interaction by tamoxifen. Cell, 95(7), 927-937.

Takano Y, Houk K. N. (2005). Benchmarking the conductor-like polarizable continuum model (CPCM) for aqueous solvation free energies of neutral and ionic organic molecules. Journal of Chemical Theory and Computation, 1(1), 70-77.

Tošović J, Marković S. (2018). Reactivity of chlorogenic acid toward hydroxyl and methyl peroxy radicals relative to trolox in nonpolar media. Theoretical Chemistry Accounts, 137(6), 76.

Turrens J. F. (2003). Mitochondrial formation of reactive oxygen species. The Journal of physiology, 552(2), 335-344.

Wang L, Yang F, Zhao X, Li Y. (2019). Effects of nitro- and amino-group on the antioxidant activity of genistein: A theoretical study. Food Chemistry, 275, 339-345.

Zhao Y, Truhlar D. G. (2008). The M06 suite of density functionals for main group thermochemistry, thermochemical kinetics, noncovalent interactions, excited states, and transition elements: two new functionals and systematic testing of four M06-class functionals and 12 other functionals. Theoretical Chemistry Accounts, 120(1-3), 215-241. 